\title{
THE ENDOCRINES IN THEORY AND PRACTICE
}

\author{
This article is one of a series on Endocrinology contributed by invitation
}

\section{THE RELATION OF THE HYPOTHALAMUS TO THE PITUITARY GLAND}

\author{
BY
}

\author{
E. C. DODDS, M.V.O., M.D., D.Sc., F.R.C.P. \\ AND
}

\section{R. L. NOBLE, M.D.Toronto}

The apparent relation of the hypothalamus to the posterior lobe of the pituitary gland was first suggested from the observations that the condition of diabetes insipidus could be successfully treated by injections of pituitary extract. Clinically, various disturbances in fat and carbohydrate metabolism, body-heat regulation, and dysfunction of the sex glands, as well as diabetes insipidus, have been described as originating from hypothalamic damage. Considerable confusion, however, has been caused in trying to assess whether such changes are due primarily to brain damage or to associated lesions of the pituitary gland, since the pathological process is seldom one confined to a localized area. Experimental conditions have made it possible to produce controlled areas of damage and reproduce most of the changes found clinically.

\section{Anatomical and Functional Relations}

The intimate connexion of the posterior lobe of the pituitary gland with the tuber cinereum by the infundibulum and pituitary stalk is well known. The tuber cinereum, forming part of the floor of the third ventricle, extends from the optic commissure in front to the mammillary bodies behind. Laterally it is continuous with the anterior perforated substance, the sublenticular region, and the ventral surface of the anterior part of the thalamus.

Cloake $^{1}$ describes the following groups of large cells found in this region.

1. The ventral nucleus of the tuber, near its ventral surface, continuous behind with the large cells of the corpus mammillare.

2. The paraventricular nuclei arranged around the anterior pillars of the fornix close to the lateral wall of the third ventricle on each side.

3. The nuclei of the optic tracts on each side, subdivided by Spiegel and $Z$ weig into the supra-chiasmatic nucleus and the supra-optic nucleus.

4. The accessory supra-optic nuclei, one on each side.

A well-defined bundle of fibres found in the pituitary stalk is said to come chiefly from the nucleus supraopticus, and runs to the posterior lobe of the pituitary gland. A detailed description of the anatomy and neural connexions of this region is given by Beattie. ${ }^{2}$

The close anatomical relation between the nuclei of the tuber region and the pituitary gland has led to the suggestion that a secretion from the posterior lobe is intimately associated with hypothalamic function. Cushing $^{3}$ suggests that a normal sequel of changes occurs as follows: viable cells, as first described by Herring, pass from the intermediate lobe of the pituitary into the posterior lobe ; here they become transformed into hyaline bodies which stream upwards towards the ventricle between what appear to be loosely textured, long-drawnout tails of ependymal glia. In support of such a theory is the evidence that experimental obstruction of the hypo- physeal stalk leads to a damming back of the secretory product and large masses of hyaline are found in the gland. Whether such a secretion acts directly on nerve centres of the tuber or first passes into the cerebro-spinal fluid is a matter of some controversy. Recently Gersh and Tarr $^{4}$ have suggested from histological studies that the so-called hyaline bodies of Herring are artefacts and do not represent a secretory product. Frank ${ }^{5}$ and others have shown that the pars tuberalis, which does not contain extractable posterior lobe hormones, may, following hypophysectomy, take on the function of secreting these hormones. These observations suggest that an exceedingly close relation must be present in the formation and action of the secretory products.

\section{Diabetes Insipidus}

The frequency with which diabetes insipidus has been found clinically in association with lesions in the hypothalamic region leaves no doubt about the general nature of its aetiology. The intensive polyuria frequently associated with tumours of the pituitary region, or following operative intervention in this area, has been described by Cushing and many others. A similar condition due to involvement of the hypothalamic region in chronic epidemic encephalitis or to basal meningitis of various types has often been recorded. Attempts to determine the exact location of the lesion giving rise to the urinary symptoms are obviously difficult because of the general nature of the pathological process. Cushing describes twenty-two cases of chiasmal gliomas of which nine had definite polyuria. Such tumours tend to invade and destroy the region of the supra-optic nuclei rather than the pituitary gland. Eaves and $\mathrm{Croll}^{6}$ have found after careful histological studies that in chronic epidemic encephalitis there are often changes in the pituitary gland. They have also shown that severe lesions in the hypothalamic region, associated with this disease, do not give rise to diabetes insipidus but that less intense lesions may do so.

Experimental diabetes insipidus has been successfully induced by a number of operative procedures. It is extremely difficult, however, at the present time to determine exactly what relation the pituitary may bear to this condition. Only a brief outline of this work can be given, but articles by Staemmler ${ }^{7}$ and by Ranson ${ }^{8}$ review this subject in detail. Much evidence can be found to show that persistent polyuria may be brought about by lesions in the supra-optic nuclei or in the pituitary stalk. In a series of cats Fisher, Ingram, and Ranson $^{8}$ have produced diabetes insipidus by bilateral injury to the supra-optico-hypophyseal system. This resulted in marked atrophy of the supra-optic nuclei and posterior lobe of the pituitary. Unilateral damage to the system did not give rise to polyuria, and large lesions in other parts of the hypothalamus had no effect. This has been confirmed by them ${ }^{9}$ in monkeys. A transitory polyuria which starts immediately after the operation has been described. This is not present in all animals which develop the permanent condition, and has been ascribed to an irritation of the anterior pituitary. In support of this is the finding that anterior transplants may lead to a marked diuresis which ceases on their removal, ${ }^{10}$ and that extracts of this lobe may on injection cause a great increase in urine secretion. ${ }^{1112} 13$ 
It is generally agreed that complete removal of the pituitary gland is not succeeded by permanent polyuria; a transitory effect, however, may often occur. Camus and Roussy ${ }^{14}$ believe that any effect following hypophysectomy is due to an associated damage to the pituitary stalk. Richter ${ }^{15}$ has found that permanent diabetes insipidus can be produced in rats by removal of the posterior lobe alone, the degree of permanency of this condition apparently being related to the amount of anterior lobe remaining.

From the experimental evidence it is impossible to form any definite theory of the production of polyuria. It would at first appear that any interference with the posterior pituitary-hypothalamic connexion might alter the secretion of an anti-diuretic pituitary hormone. The finding, however, that transient polyuria may be brought about by hypothalamic puncture in an animal after previous hypophysectomy, ${ }^{16}{ }^{17} 18$ and that pituitary removal itself does not permanently affect the animal, indicates that it is not yet possible to give a complete explanation of this problem.

The anti-diuretic action of pituitary extracts is stated to be directly on the kidney, ${ }^{19}$ but the mechanism of the diuretic action of hypothalamic damage is not clear. Cross-circulation experiments have been described which demonstrated a polyuria-producing substance transmissible through the blood stream. This substance was supposedly produced after hypophysectomy. ${ }^{20} 21$ There is considerable evidence to show that denervation of the kidney does not alter the polyuria following tuber injury. ${ }^{22}{ }^{23}$ Transection of the brain stem or spinal cord and double vagotomy have also been found to have no effect on the production of diabetes insipidus. ${ }^{24}$ At the present time it may be stated that an interference with the supraoptic nuclei of the hypothalamus, the posterior lobe of the pituitary, or their connexions may result in permanent polyuria. Evidence would appear to favour a hormonal alteration of some kind affecting the kidney and leading to the condition of diabetes insipidus.

\section{Glycosuria, Adiposity, and Genital Atrophy}

Descriptions of cases with glycosuria, adiposity, and genital atrophy attributed to hypothalamic damage are numerous. Whether such findings are due to an associated pituitary dysfunction or primarily to the brain lesion is exceedingly difficult to prove. Experiments to induce such changes by hypothalamic damage in the absence of the pituitary gland are not easy to interpret because of the effects on carbohydrate and fat metabolism and on the reproductive system caused by hypophysectomy itself. Smith, ${ }^{25}$ however, states that with both a pituitary and a tuber injury in a young animal the adiposo-genital syndrome of Fröhlich may develop. Transient glycosuria may occur in a normal animal after a variety of nervous lesions. Tuber lesions in $\operatorname{dogs}^{26}$ and in rats ${ }^{14}$ may cause glycosuria, probably without altered pituitary secretion. No antagonistic action as in diabetes insipidus can be postulated, however, as both anterior and posterior lobe extracts are known to cause hyperglycaemia. The demonstration that degeneration of the paraventricular nucleus follows diabetic puncture in the floor of the fourth ventricle has led to the suggestion that the nucleus may be a regulator of sugar metabolism by maintaining sympathetic and parasympathetic centres in equilibrium. ${ }^{1}$ It has also been stated that there are changes in the paraventricular nucleus after experimental pancreatectomy. ${ }^{27}$ That such a mechanism could be influenced by the pituitary gland is possible, but there is little direct evidence to suggest such an action. Cushing, after studying the effects of pituitrin injected into the ventricles of the brain, has suggested that this substance may have a normal stimulating effect on the brain of a parasympathetic type. Controlled experiments with purer pituitary preparations, however, give a less effective response, so that the effect must be considered at the present time of questionable specificity.

That marked adiposity may occur in patients with tumours of the tuber region is well established. Cushing finds that tumours which involve the tuber are more frequently associated with adiposity than are intrasellar lesions. Adiposity is a feature of basophil adenomas of the anterior lobe of the pituitary. From the experimental studies of Bailey and Bremer, Roussy and Smith, it has been shown that tuber damage without pituitary injury may frequently lead to adiposity. Gournay and Le Grand found the paraventricular nucleus always injured in dogs which developed obesity after tuberal puncture. ${ }^{28}$ The effect of giving pituitary extract to these obese animals does not appear to have been studied, but Cushing states that adiposity may develop as a result of blockage to pituitary secretion by tuber clips.

Atrophy of the sex organs after hypothalamic injury is difficult to interpret in view of the similar effects produced by removal of the anterior lobe of the pituitary. Experimentally, atrophy of the gonads would appear to have occurred without evidence of damage to the pituitary gland. ${ }^{25}$ It has been suggested that a possible interference with the blood supply of the gland may have caused these changes. The fact, however, that there were no histological changes in the pituitary, thyroid, or adrenals and that genital atrophy does not arise until a large amount of pituitary tissue is destroyed would suggest that hypothalamic damage may alter the normal mechanism of gonad function. It is of interest to note in this connexion that ovulation may be induced in the rabbit by electrical stimulation of the brain or spinal cord. The impulses pass by some route to stimulate the secretion of the anterior lobe of the pituitary gland which acts on the ovary. ${ }^{29}$ Other changes, such as loss of temperature regulation and pathological sleep, have been observed in association with brain tumours involving hypothalamic centres. Similar conditions have been found to accompany experimental lesions or hypophysectomy. The relationship of the pituitary, however, has not been investigated in enough detail to conclude what influence it may have over such changes.

\section{Stomach Lesions}

Gastric hypermotility and hypersecretion have been shown by Beattie $^{30}$ and others to follow direct stimulation of tuberal centres. In some animals peptic ulcers, which may perforate, develop. Such an effect does not arise after section of the vagus nerves, and appears to be due to a stimulation of the parasympathetic nervous system. That the pituitary gland may be closely associated with gastric function has been suggested by the finding of gastric ulcers in cases of pituitary tumours ${ }^{31} 32.33$; also, D'Amour $^{34}$ has shown that haemorrhagic erosions may occur in the stomach mucosa after hypophysectomy in animals. The demonstration by the authors ${ }^{35} 36$ that extracts of the posterior lobe of the pituitary bring about a severe alteration in the secretion of the stomach and also induce typical chronic ulcers would suggest that a normal pituitary-hypothalamic control may be present.

\section{Summary}

A series of disturbances found in clinical cases of lesions in the hypothalamic region have been reproduced in experimental studies. The part which the pituitary gland may play in such changes is still obscure; but the close anatomical relationship and the effects of the 
injection or removal of pituitary hormones suggest the probability of some normal functional relationship between this gland and the hypothalamus.

REFERFNCES

${ }^{1}$ Cloake, P.: Proc. Roy. Soc. Med, 1927, xx, 1643.

2 Beattie, J.: Canadian Med. Assoc. Journ., 1932, xxvi, 400

${ }^{3}$ Cushing, H.: Pituitary Body and Hypothalamus, London, 1932

- Gersh, I., and Tarr, A. de L.: Anat. Record, 1935, lxiii, 231.

srank, E.: Med. Klin., 1929, xxv, 699

- Eaves, Elizabeth Cowper, and Croll, Margaret M.: Brain, 1930 liii, 56

'Staemmler, M.: Ergbn. d. allg. Path. u. Path. Anat., 1932 xxvi, 59

- Fisher, C., Ingram, W. R., and Ranson, S. W.: Arch. Neurol. and Psychiat., 1935, xxxiv, 124

- Ingram, W. R., Fisher, C., and Ranson, S. W.: Arch. Int. Med., 1926, lvii, 1067.

${ }^{10}$ Crowe, S. J., Cushing, H., and Homans, J.: Quart. Journ. Exp. Physiol 1909 ,ii, 389.

11 Teel, H. M.: Journ. Amer. Med. Assoc., 1929, xciii, 760.

Barnes, B. O., Regan, J. F., and Bueno, J. G.: Amer. Journ. Physiol., 1933, cv, 559.

${ }^{13}$ Biasotti, A.: C. R. Soc. de Biol., 1934, cxv, 329.

"Camus, J., and Roussy, G.: Journ. Physiol. et Path. Gén. 1922, $\mathrm{xx}, 509$

${ }^{15}$ Richter, C. P.: Amer. Journ. Physiol., 1934, cx, 439.
${ }^{16}$ Camus, J., and Roussy, G.: C. R. Soc. de Biol., 1913, lxxv, 628

7 Houssay, B., Carulla. J. E., and Romana, L.: Ibid., 1920, Ixxxiii, 1250 .

18 Warner, F. J.: Journ. Nerv. and Ment. Dis., 1931, lxxiii, 375.

19 Wright, S.: Applied Physiology, London, 1936.

${ }^{20}$ Compire, A.: Arch. Internat. de Physiol., 1933, xxxvi, 54

${ }^{21}$ Brull, L.: Presse Méd., 1933, xli, 1267.

${ }^{22}$ Houssay, B., and Carulla, J. E.: C. R. Soc. de Biol., 1920, lxxxiii, 1252 .

${ }^{23}$ Camus, J., and Bournay, J. J.: Ibid., 1923, 1xxxviii, 694.

24 Bourquin, H.: Amer. Journ. Physiol., 1931, xcvi, 66.

25 Smith, P. E.: Journ. Amer. Med. Assoc., 1927, Ixxxviii, 158.

20 Bailey, P., and Bremner, F. : Arch. Int. Med., 1921, xxvii, 773.

${ }_{27}$ Urechia, C. I., and Nitescu, I.: Bull. de l'Acad. de Méd., 1925 (February), xliii (third series).

${ }^{28}$ Gournay, J. J., and Le Grand, A. : Ann. de Méd., 1925, xviii, 434.

${ }^{29}$ Marshall, F. H. A., and Verney, E. B.: Journ. of Phy'siol., 1935, lxxxv, 12 (Proceedings).

${ }^{30}$ Beattie, J.: Canadian Med. Assoc. Journ., 1932, xxvi, 278.

${ }^{31}$ Close, H. G.: British Medical Journal, 1935, i, 356

32 Swan, W. G. A., and Stephenson, C. E.: Lancet, 1935, i, 372.

33 Swan, W. G. A., and Stephenson, C. . 1933, clxxxxvi, 568.

s Keller, A. D., D'Amour, M. C., and Hare, W. K.: Amer. Journ. Physiol., 1934, cix, 63.

ss Dodds, E. C., Noble, R. L., and Smith, E. R.: Lancet, 1934, ii, 918.

${ }^{36}$ Dodds, E. C., Hil!s, G. M., Noble, R. L., and Williams, P. C.: Ibid., 1935, i, 1099.

\section{THE NATION'S HEALTH SERVICES}

\section{ANNUAL REPORT OF THE MINISTRY}

The activities of the Ministry of Health as described in its annual report suggest the concerns of a busy and effcient mother in a large household, ever looking to the cleansing of her dwelling, the replenishment of her cupboards, the assortment of her laundry, and at the same time diligently scrutinizing her domestic budget. An extraordinary range of public affairs is covered, including a great deal-such as local finances, county boundaries, and borough charters-which has no direct health interest. The large health questions are institutional provision for the sick, domiciliary medical relief, maternity and child welfare, accommodation for infectious diseases, seaport (and now also airport) sanitary administration, lunacy and mental deficiency, adulteration of foods, water supply, sewage disposal, public cleansing and recreation, and beyond these the great fields of national health insurance service and public assistance, housing, and town and country planning.

\section{Provision for the Sick}

The report for $1935-6^{1}$ is largely statistical, almost wholly so in its forty-four appendices, which, if one can read figures with imagination, are the most interesting part of the document. From one of these it can be discovered that the total number of institutions or hospitals under the Poor Law Act in England (Wales is dealt with as a separate section) is now 448 , with 71,856 beds, and of general hospitals under the Local Government or Public Health Acts ninety-three, with 50,508 beds. The total number of beds occupied in all these institutions at the end of last year was 101,482, and during the year there were 678,455 admissions, and nearly one million and a half out-patient attendances. All these figures are growing except those of Poor Law institutions. Reference is made in the body of the report to the importance of co-operation between voluntary hospitals and local authorities in the provision and utilization of accommodation for the sick, and also of co-operation between local authorities themselves in the use of institutions transferred to them under the Local Government Act.

For domiciliary medical relief the system under operation over the greater part of the country is the appointment as district medical officers of practitioners in private practice. Certain authorities have recently adopted experimentally over the whole or part of their areas a system

${ }^{1}$ Seventeenth Annual Report of the Ministry of Health. H.M. Stationery Office. Cmd. 5287. (5s. net.) whereby domiciliary relief is provided by a panel of practitioners. Up to April last such arrangements had been made in parts of seven counties and in the whole or parts of six county boroughs.

\section{Maternity Care}

Further regiments of impressive figures march into view when the report comes to deal with maternity and child welfare services. The number of ante-natal clinics increased from 1,396 at the end of 1934 to 1,491 at the end of 1935. Infant welfare centres, which are almost twice as numerous as ante-natal clinics, show a similar increase. Here again an appendix affords useful information. The total number who attended ante-natal clinics in the year (including clinics provided both by local authorities and by voluntary associations) was 273,423 a. figure equal to nearly half the total notified births. The average number of attendances per woman at these ante-natal clinics was four.

Some idea of institutional maternity in so far as it takes place under the provision made by local authorities is afforded. There are ninety institutions in England, with 1,558 beds, provided by local authorities wholly for maternity patients, and there are 4,223 further maternity beds in the wards of 363 other institutions transferred under the Local Government Act. The institutions belonging to voluntary associations and providing accommodation subsidized by local authorities numbered 131, with 2,133 beds. Altogether the number of women who had what might be called a " council confinement " during the year was 147,288 , and the demand for maternity beds shows a steady increase.

The maternal mortality figure for England and Wales in 1935 was only 3.93 per 1,000 live and still births (1.61 for deaths from puerperal sepsis and 2.32 for deaths from other causes), a reduction of $\mathbf{0 . 4 8}$ on the 1934 figure, and the lowest rate since 1925 . The marked reduction is in deaths from puerperal sepsis. Although the number of live births was slightly higher in 1935 than in the previous year, the number of maternal deaths was nearly 300 fewer. The report states:

"Experience has shown that, where domiciliary midwifery services are provided on a properly organized basis by the salaried midwives of voluntary hospitals and nursing associations, the maternal mortality rato is well below the national rate, and it is considered that the organization of a service of salaried midwives in all areas should do much to secure a reduction of that rate. The Bill [now the Midwives Act 1936] is also intended to raise the status of the midwives profession by providing adequate salaries and sccure prospects for midwives entering the new service."

The number of candidates who received the certificate of the Central Midwives Board during the last recorded year was 2,936 , a slight reduction on the previous year's 